\title{
Co-administration of 5-HT6 receptor antagonists with clozapine, risperidone, and a 5-HT2A receptor antagonist: effects on prepulse inhibition in rats
}

\author{
Katarzyna Fijal • Piotr Popik • Agnieszka Nikiforuk
}

Received: 9 January 2013 / Accepted: 28 July 2013 /Published online: 18 August 2013

(C) The Author(s) 2013. This article is published with open access at Springerlink.com

\begin{abstract}
Rationale Some novel antipsychotics manifest antagonistic activity at serotonin- 6 receptors; however, little is known about the role of 5-HT6 receptors in ameliorating sensory gating deficits.

Objective We evaluated the effects of the combined administration of the 5-HT6 receptor antagonist SB 271046 with clozapine and haloperidol, as well as the co-administration of SB 271046 or SB 399885 with risperidone and the 5-HT2A antagonist M100907, to overcome the deficits induced by MK-801 in the prepulse inhibition (PPI) test.

Results MK-801 (0.1 mg/kg) produced reliable PPI deficits. Administration of SB 271046 (6 and $9 \mathrm{mg} / \mathrm{kg}$ ), SB 399885 (3 and $6 \mathrm{mg} / \mathrm{kg})$, clozapine $(2.5 \mathrm{mg} / \mathrm{kg})$, haloperidol $(0.1$ and $0.2 \mathrm{mg} / \mathrm{kg})$, risperidone $(0.25-1 \mathrm{mg} / \mathrm{kg})$, and M100907 (0.5 and $1 \mathrm{mg} / \mathrm{kg}$ ) did not affect the MK-801-induced deficits, but the administration of clozapine $(5 \mathrm{mg} / \mathrm{kg})$ did reverse the effects of MK-801. In MK-801-treated rats, the coadministration of inactive doses of clozapine $(2.5 \mathrm{mg} / \mathrm{kg})$ and SB 271046 (6 mg/kg) reversed the PPI impairments compared to animals that were administered inactive doses of either clozapine or SB 271046 alone. Co-administration of risperidone $(1 \mathrm{mg} / \mathrm{kg})$ or M100907 $(0.5 \mathrm{mg} / \mathrm{kg})$ with SB 271046 $(6 \mathrm{mg} / \mathrm{kg})$ or SB $399885(3 \mathrm{mg} / \mathrm{kg})$ also attenuated the MK801-induced PPI deficits. In contrast, joint administration of haloperidol and SB 271046 had no effect on the PPI deficit. Conclusion The present results suggest that the 5-HT6 receptors may play adjunctive roles in antipsychotic drug action, and that the combination of 5-HT2A and 5-HT6 antagonism may represent an important element in the pharmacological profile of antipsychotic drugs.
\end{abstract}

K. Fijał $\cdot$ P. Popik $(\triangle) \cdot$ A. Nikiforuk Department of Behavioral Neuroscience and Drug Development, Institute of Pharmacology, Polish Academy of Sciences, 12 Smętna Street, 31-343 Kraków, Poland

e-mail: nfpopik@cyf-kr.edu.pl
Keywords 5-HT6 receptor $\cdot 5$-HT2A receptor - Clozapine . Risperidone $\cdot$ Prepulse inhibition · Startle response · Schizophrenia $\cdot$ Antipsychotics

\section{Introduction}

Serotonin (5-HT) receptor signaling plays a key role in the efficacy of a new generation of antipsychotic drugs. The efficacy of atypical antipsychotics has been attributed to a weaker dopamine D2 receptor blockade and stronger action at serotonergic receptors (Newman-Tancredi and Kleven 2011). Clozapine is a prototype of a second-generation antipsychotic drug, and its therapeutic potential has been associated with higher affinity for the 5-HT2A receptor than the D2 receptors (Meltzer et al. 1989). Clozapine also demonstrates high affinity for the 5-HT2C, 5-HT3, 5-HT6, and 5-HT7 receptors. The efficacy of clozapine to treat various symptoms of schizophrenia-like psychoses has been attributed to its complex, multi-receptor profile; however, it has not been determined which receptor subtypes or combination of receptors contribute to its therapeutic properties.

Converging lines of evidence have indicated that 5-HT6 receptors are an interesting target for the development of novel antipsychotics. First, 5-HT6 receptors have been proposed to modulate neurotransmitter systems in the brain regions implicated in schizophrenia, and antagonists of 5-HT6 receptors administered alone or in combination with other drugs enhance dopamine and glutamate efflux in the medial prefrontal cortex and hippocampus ( $\mathrm{Li}$ et al. 2007; Mork et al. 2009). Furthermore, a number of studies suggest that the 5-HT6 receptors are implicated in cognitive functions, which are compromised in schizophrenic patients (Mitchell and Neumaier 2005; Mitchell and Neumaier 2008; Meneses et al. 2011). Some novel antipsychotics, which are also potent 5-HT6 receptor antagonists, display pro-cognitive effects in patients (Cincotta and Rodefer 2010; Hale et al. 2012). The 
putative role of 5-HT6 receptors in cognitive disorders has been supported by a number of animal studies. Thus, 5-HT6 receptor antagonists have been shown to improve learning and memory as evaluated by diverse behavioral procedures (Hirst et al. 2006; Arnt et al. 2010). Moreover, they enhance cognitive flexibility in the attentional set shifting task (Hatcher et al. 2005; Rodefer et al. 2008), a model used to assess the prefrontal flexibility that is compromised in schizophrenic patients.

Studies evaluating the role of 5-HT6 receptors in ameliorating prepulse inhibition (PPI) deficits provide less consistent results. For instance, the 5-HT6 antagonist SB 271046 has been reported to exert a beneficial effect on amphetamine, but not PCP-induced PPI deficits (Pouzet et al. 2002), while the other 5-HT6 antagonists Ro 04-6790 and Ro 65-7199 failed to reverse the PPI disruption evoked by LSD, apomorphine, and PCP (Leng et al. 2003). Another 5HT6 antagonist Ro-4368554, but not SB 258585, was effective in attenuating the apomorphine-induced prepulse inhibition deficit (Gravius et al. 2011). Our own unpublished findings suggest that sertindole, an antipsychotic with high 5-HT6 receptor affinity, reversed the PPI deficit evoked by MK-801.

The aim of the present study was to further explore the involvement of 5-HT6 receptors in the action of antipsychotic drugs using prepulse-induced inhibition of the acoustic startle procedure (PPI), a paradigm in which both schizophrenic patients and animals treated with drugs mimicking some aspects of psychoses demonstrate similar deficits. The reversal of PPI deficits has been considered to demonstrate predictive validity for the detection of antipsychotic drug action, and PPI is regarded as a model of attention and information processing (Braff and Geyer 1990; Swerdlow et al. 2000). We induced a PPI deficit by acute administration of MK-801, a glutamate NMDA receptor antagonist with psychoto-mimetic properties (Rujescu et al. 2006), thereby mimicking the neuropsychological impairments that are characteristic of schizophrenic patients. The disruptive effects of MK-801 on PPI in animals have been well documented; for review, see Geyer et al. (2001).

We first assessed the effects of clozapine in MK-801treated rats. Because previous reports provide conflicting results regarding the ability of clozapine to reverse the MK-801induced PPI deficits in rats (Hoffman et al. 1993; Bubenikova et al. 2005; Gururajan et al. 2011), we evaluated clozapine's actions using a standard and a modified PPI protocol. To examine whether 5-HT6 receptor inhibition could contribute to the antipsychotic-like effects, we evaluated the effects of the 5-HT6 receptor antagonist SB 271046 alone and in combination with the multi-receptor (5-HT2A, 5-HT6, D2) clozapine, the 5-HT2A/D2 (but not 5-HT6) preferential risperidone, the D2-preferential haloperidol, and the 5-HT2A antagonist M100907. The effects of the combined treatment of the
5-HT6 receptor antagonist with risperidone and with M100907 on prepulse inhibition were also investigated using another 5-HT6 antagonist, SB 399885, which has been characterized as having a better brain penetrability (Upton et al. 2008).

\section{Materials and methods}

Animals

Male rats of the Sprague-Dawley strain were supplied by Charles River (Germany). Animals were approximately 2 months old and weighed $350-400 \mathrm{~g}$ at the time of the experiment. Rats were housed four per cage with free access to food and water and were kept in an $\mathrm{A} / \mathrm{C}$ controlled environment with a 12/12 light-dark cycle (lights on at 0600). All experimental procedures were approved by the ethics Committee of the Institute of Pharmacology, Polish Academy of Sciences in Kraków.

\section{Drug administration}

MK-801 maleate (Abcam Biochemicals, Cambridge, UK) was dissolved in distilled water and administered subcutaneously (s.c.) at a dose of $0.1 \mathrm{mg} / \mathrm{kg}$. SB 271046 hydrochloride and SB 399885 hydrochloride (TOCRIS Bioscience, Park Elisville, MO, USA) were dissolved in $0.5 \%$ methylcellulose and administered intraperitoneally (i.p.) at doses of 6 and $9 \mathrm{mg} / \mathrm{kg}$ (SB 271046) or 3 and $6 \mathrm{mg} / \mathrm{kg}$ (SB 399885). Clozapine (Abcam Biochemicals, Cambridge, UK) was dissolved in $0.1 \mathrm{~N} \mathrm{HCl}$ supplemented with distilled water to the appropriate volume (final $\mathrm{pH}=5.0-6.0$ ) and administered i.p. at doses of 2.5 and $5 \mathrm{mg} / \mathrm{kg}$. Haloperidol (SigmaAldrich, St. Louis, MO, USA) was dissolved in $0.1 \mathrm{~N} \mathrm{HCl}$ supplemented with distilled water and administered i.p. at doses of 0.1 and $0.2 \mathrm{mg} / \mathrm{kg}$. Risperidone (Abcam Biochemicals, Cambridge, UK) was dissolved in $0.1 \mathrm{~N} \mathrm{HCl}$ supplemented with distilled water and administered i.p. at doses of 0.25, 0.5, and $1 \mathrm{mg} / \mathrm{kg}$. M100907 (Sigma-Aldrich, St. Louis, MO, USA) was dissolved in warm $0.015 \%$ Tween- 80 and administered s.c. at doses of 0.5 and $1 \mathrm{mg} / \mathrm{kg}$. The dose of MK-801 $(0.1 \mathrm{mg} / \mathrm{kg})$ is expressed as a free base; whereas, the doses of other compounds are expressed as salts. The drugs or their respective vehicles were injected in a volume $1 \mathrm{~mL} / \mathrm{kg}$.

\section{Apparatus}

Rats were tested in the startle response apparatus (Med Associates, St. Albans, VT), which consisted of acrylic animal holders with a grid floor made of stainless bars and was mounted on a startle platform; the apparatus was placed in a 
ventilated, sound-attenuating chamber. Acoustic stimuli were generated by two speakers: the background noise speaker and a stimulus speaker, placed at the back of the chamber $7 \mathrm{~cm}$ from the animal holder. Startle responses were detected and transduced by the load cell and were digitized and stored using the Startle Reflex software (Med Associates, St. Albans, VT, version 5).

\section{PPI test procedure}

The rats, which were used only once, were subjected to two pre-test sessions: the afternoon session on the day before testing and the morning session on the test day. This procedure, adopted from the published protocols (Auclair et al. 2006; Long et al. 2006), was performed to habituate the animals to the apparatus as the PPI test has been shown to produce highly variable responses to the startle stimuli. Rats were divided into groups based on their mean pulse amplitude obtained in the first pre-test session. The pre-test on the test day was performed approximately $2 \mathrm{~h}$ before the pharmacological challenge. The experimental protocols used during the pre-test and test sessions were identical.

Sessions started with a 5-min acclimatization period. A 62-dB background white noise was continuously presented once animals were placed inside the test chambers and was maintained throughout the entire session. The following types of acoustic stimuli were used in the test protocol: pulse alone [intensity, $120 \mathrm{~dB}$; duration, $40 \mathrm{~ms}$, $(\mathrm{P})$ ], pulse preceded by an acoustic prepulse of intensities 70,73 , and $76 \mathrm{~dB}$ [duration, $20 \mathrm{~ms}$; (PP)] applied $100 \mathrm{~ms}$ before the pulse $(\mathrm{P})$, prepulse alone [intensity 70,73 , and $76 \mathrm{~dB}$, duration $20 \mathrm{~ms}$ ], and a null period. The session consisted of three blocks. During the first block, the animals were exposed to 10 pulse alone trials. During the second block, the following trials were presented in random order: pulse alone, pulse preceded by each prepulse, along with 1 repetition of each prepulse alone, and 4 null trials. The inter-trial interval was $20 \mathrm{~s}$. The third block consisted of 10 pulse alone trials.

Prior to the proper experiments 2-6, a series of tests were conducted to optimize the PPI protocol to study the effects of the compounds. We used two types of test sessions. In experiment 1 , the test session consisted of 10 repetitions of each trial type, and the PPI values were calculated for the total duration of the test session as well as for the first part of the session, which consisted of 4 presentations of each trial type. Because the preliminary experiment (see Fig. 1) demonstrated that 4 presentations of each trial type produced a reliable effect when the rats were treated with clozapine, compared to the more common 10 presentations protocol, in experiments 2-6, we used 4 repetitions of each trial type. All experiments were conducted during the light phase.

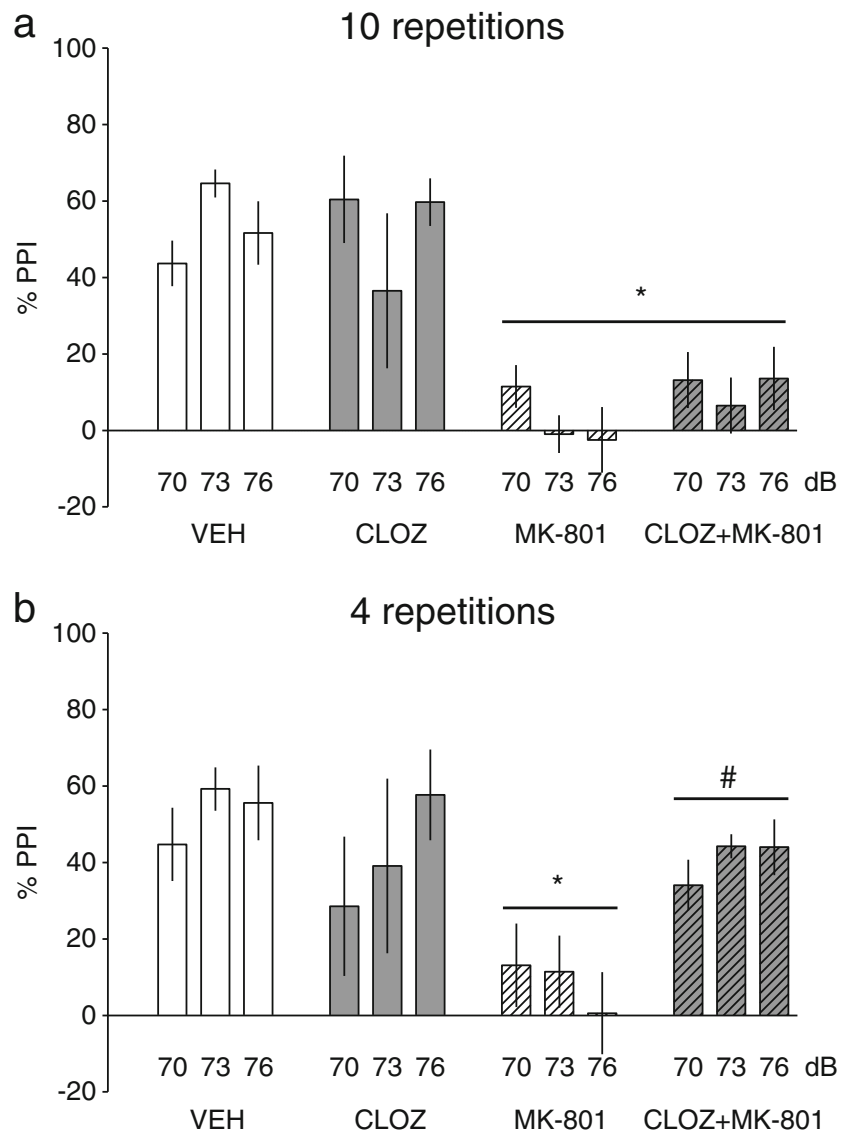

Fig. 1 The number of repetitions of the stimuli presentations determines the efficacy of clozapine (CLOZ; $5 \mathrm{mg} / \mathrm{kg}$ ) in reversing an MK801 -induced $(0.1 \mathrm{mg} / \mathrm{kg})$ PPI deficit. a Results of the experiment consisting of ten repetitions of each trial type. $\mathbf{b}$ Results of the experiment consisting of four repetitions of each trial type. PPI was evaluated at three prepulse intensities $(70,73$, and $76 \mathrm{~dB})$. The results are expressed as the means \pm S.E.M. Symbols: ${ }^{*} P<0.05$ the main effect of MK-801 on PPI or MK-801 effects versus the vehicle; $\# P<0.05$ versus the MK-801 treatment. For the detailed number of animals tested, see Table 1

Experimental design

Experiment 1: effects of the number of repetitions of stimuli presentations on the efficacy of clozapine in reversing the MK-801-induced PPI deficit

Animals were pretreated with either the vehicle or clozapine $(5 \mathrm{mg} / \mathrm{kg})$, and $10 \mathrm{~min}$ later, they received either the vehicle or MK-801 $(0.1 \mathrm{mg} / \mathrm{kg})$. A dose of $0.1 \mathrm{mg} / \mathrm{kg}$ MK-801 was chosen for all experiments because it produces robust PPI deficits (Bast et al. 2000). Fifteen minutes after the MK-801 injection, the rats were placed in the startle chambers, and the session was started. The PPI values were computed for the total duration of the test session (10 repetitions for each trial type) as well as for the first part of the session, which consisted of 4 repetitions of each trial type. 
Experiment 2: effects of 5-HT6 receptor antagonists $S B$ 271046 and SB 399885 on the PPI deficit evoked by MK-801

Because experiment 1 revealed that clozapine effectively attenuated the MK-801-induced PPI deficit with 4, but not 10, repetitions of the stimuli presentations, we used the shorter protocol for all further studies. Experiment 2 tested whether the 5-HT6 antagonists SB 271046 and SB 399885 could normalize the PPI deficit evoked by MK-801. Animals were pretreated with either the vehicle, SB 271046 (6 and $9 \mathrm{mg} / \mathrm{kg}$ ) or SB 399885 (3 and $6 \mathrm{mg} / \mathrm{kg}$ ), and $15 \mathrm{~min}$ later, they were treated with either the vehicle or MK-801 $(0.1 \mathrm{mg} / \mathrm{kg})$. The doses of SB 271046 were selected based on the dose range tested against psychoactive drugs in the PPI model (Pouzet et al. 2002); the doses of SB 399885 were lower due to its better brain penetrability (Upton et al. 2008). Fifteen minutes after MK-801 injection, the rats were placed in the startle chambers, and the session was started.

\section{Experiment 3: effects of clozapine alone and in combination with SB 271046 on the PPI deficits evoked by MK-801}

Experiment 3 was conducted in two steps. We first examined the effects of clozapine (2.5 and $5 \mathrm{mg} / \mathrm{kg}$ ) on the startle amplitude and PPI deficits induced by MK-801 $(0.1 \mathrm{mg} / \mathrm{kg})$, which was administered $10 \mathrm{~min}$ after clozapine. The choice of the clozapine dose used was based on its ability to reverse PPI impairments in various pharmacological models (Bakshi et al. 1994; Bubenikova et al. 2005) and in preliminary studies conducted in our laboratory. Fifteen minutes after MK-801 injection, the rats were placed in the startle chambers, and the session was started.

The following test was conducted to investigate the effects of co-administration of an inactive dose of clozapine and SB 271046 on the startle amplitude and PPI deficit evoked by MK-801. Animals were simultaneously pretreated with clozapine $(2.5 \mathrm{mg} / \mathrm{kg}$ or its vehicle $)$ and SB $271046(6 \mathrm{mg} / \mathrm{kg}$ or its vehicle), and $10 \mathrm{~min}$ later, they were injected with MK-801 $(0.1 \mathrm{mg} / \mathrm{kg}$ or its vehicle). Testing session started $15 \mathrm{~min}$ after MK-801 injection.

\section{Experiment 4: effects of haloperidol alone and in combination} with SB 271046 on the PPI deficits evoked by MK-801

This study was also carried out in two steps. First, the effects of haloperidol $(0.1$ and $0.2 \mathrm{mg} / \mathrm{kg})$ administration on the startle amplitude and PPI deficits induced by MK-801 were evaluated. These doses of haloperidol were within a range shown to reverse the PPI deficits evoked by apomorphine (Hart et al. 1998). Animals were pretreated with either the vehicle or haloperidol $(0.1$ and $0.2 \mathrm{mg} / \mathrm{kg}$ ), and $15 \mathrm{~min}$ later, they were treated with either the vehicle or MK-801 (0.1 mg/kg). Fifteen minutes after MK-801 injection, the testing session started.
Subsequently, the effects of a joint administration of a lower dose of haloperidol and SB 271046 on the PPI deficit evoked by MK-801 were examined. Animals were simultaneously pretreated with haloperidol $(0.1 \mathrm{mg} / \mathrm{kg}$ or its vehicle $)$ and SB $271046(6 \mathrm{mg} / \mathrm{kg}$ or its vehicle $)$ and were injected with MK-801 $15 \mathrm{~min}$ later $(0.1 \mathrm{mg} / \mathrm{kg}$ or its vehicle). The testing session started 15 min after MK-801 injection.

Experiment 5: effects of risperidone alone and in combination with SB 271046 or with SB 399885 on the PPI deficits evoked by $M K-801$

The ability of risperidone to normalize the PPI deficit elicited by MK-801 was examined first. Animals were pretreated with either the vehicle or risperidone $(0.25,0.5$, and $1 \mathrm{mg} / \mathrm{kg})$ and then treated with either the vehicle or MK-801 $(0.1 \mathrm{mg} / \mathrm{kg})$ 15 min later. These doses were selected from the prior PPI studies, which used a range of risperidone doses between 0.1 and $1 \mathrm{mg} / \mathrm{kg}$ (Bubenikova et al. 2005; McIntosh et al. 2013). Fifteen minutes after MK-801 injection, the rats were placed in the startle chambers, and the session started.

Because risperidone did not affect the PPI deficits evoked by MK-801 at any of the doses studied, the effects of the coadministration of risperidone at $1 \mathrm{mg} / \mathrm{kg}$ and SB 271046 or SB 399885 on MK-801-induced PPI deficits were studied. Rats were simultaneously injected with risperidone or its vehicle and SB 271046 (6 mg/kg or vehicle) or SB 399885 (3 mg/kg or vehicle), and $15 \mathrm{~min}$ later, they were injected with MK-801 $(0.1 \mathrm{mg} / \mathrm{kg}$ or its vehicle). The test session started $15 \mathrm{~min}$ after MK-801 injection.

\section{Experiment 6: effects of 5-HT2A receptor antagonist} M100907 alone and in combination with SB 271046 and with SB 399885 on the PPI deficits evoked by MK-801

The ability of the 5-HT2A antagonist to normalize the PPI deficit elicited by MK-801 was examined first. Animals were pretreated with either the vehicle or M100907 (0.5 and $1 \mathrm{mg} / \mathrm{kg}$ ) and were then treated with either the vehicle or MK-801 $15 \mathrm{~min}$ later $(0.1 \mathrm{mg} / \mathrm{kg})$. Fifteen minutes after MK-801 injection, the rats were placed in the startle chambers, and the session started. The dose range of M100907 was based on a prior PPI study (Varty et al. 1999) and on behavioral experiments conducted in our laboratory.

The effects of the co-administration of inactive doses of M100907 and SB 271046 or SB 399885 on the startle amplitude and PPI deficits evoked by MK-801 were then studied. Rats were simultaneously injected with M100907 (0.5 mg/kg or its vehicle) and SB 271046 (6 mg/ $\mathrm{kg}$ or vehicle) or SB 399885 (3 mg/kg or vehicle) and $15 \mathrm{~min}$ later, the animals were injected with MK-801 (0.1 mg/kg or its vehicle). The test session started 15 min after MK-801 injection. 
Data analysis

For calculations, the measures obtained in the second block were used. The mean response amplitude for the pulse alone [P] and the prepulse + pulse $[\mathrm{PP}]$ trials were computed for each rat, and PPI was determined according to the following formula:

$\operatorname{PPI}(\%)=[(\mathrm{P}-P P) / \mathrm{P}] * 100$

All data are presented as the mean \pm S.E.M. The percentage PPI data were analyzed using a three-way mixed design ANOVA with a between-subject factor of MK-801, a between-subjects factor of the respective treatments, and a within-subject factor of three prepulse intensities. The pulse amplitude values were analyzed using a two-way ANOVA with a between-subject factor of MK-801 and a betweensubject factor of the respective treatments. Whenever significant interactions were found, an ANOVA was followed by Duncan's post hoc test. A probability level of $P<0.05$ was used to determine significance.

\section{Results}

Experiment 1: effects of the number of repetitions of stimuli presentations on the efficacy of clozapine in reversing the MK-801-induced PPI deficit

MK-801 significantly reduced PPI $(F(1,17)=36.400 ; P<$ 0.001). As shown in Fig. 1a, an ameliorative effect of clozapine $(5 \mathrm{mg} / \mathrm{kg}$ ) on the PPI deficit induced by MK-801 was not detected when a session consisting of ten repetitions of each trial type was used, as the interaction between MK-801 and clozapine treatments was insignificant. While MK-801 elevated $(F(1,17)=17.931 ; P<0.01)$ and clozapine reduced $(F(1,17)=9.985 ; P<0.01)$ the startle amplitude, no significant interaction between the treatments was found on this measure (Table 1).

The reversing effect of clozapine was detected when the first four repetitions of each trial type were included in the calculations, as an ANOVA revealed a significant interaction between MK-801 and clozapine treatments $(F(1,17)=4.913$; $P<0.05$, Fig. 1b). The interaction between MK-801, clozapine, and stimuli intensity factors was insignificant. The post hoc test in the MK-801-treated rats revealed that pretreatment with clozapine $(5 \mathrm{mg} / \mathrm{kg})$ significantly elevated the PPI, compared with the vehicle pretreated group. While MK-801 elevated $(F(1,17)=23.319 ; P<0.01)$ and clozapine reduced $(F(1,17)=16.401 ; P<0.01)$ the startle amplitude, no significant interaction between the treatments was found in this measure (Table 1).
Table 1 Effects of MK-801 (0.1 mg/kg), SB 271046, SB 399885, clozapine, risperidone, haloperidol, M100907, and combinations of these drugs on the startle amplitude of rats evoked using a 120 -dB pulse tone

\begin{tabular}{ll}
\hline Drug/dose $(\mathrm{mg} / \mathrm{kg})$ & Startle N \\
\hline
\end{tabular}

Experiment 1

$\begin{array}{lll}\text { A } 10 \text { repetitions } & & \\ \text { Veh+Veh } & 625 \pm 100 & 5 \\ \text { MK-801+Veh } & 1,096 \pm 107 & 5 \\ \text { Clozapine (5.0)+Veh } & 400 \pm 118 & 5 \\ \text { Clozapine (5.0)+MK-801 } & 726 \pm 50 & 6 \\ \text { B 4 repetitions } & & \\ \text { Veh+Veh } & 799 \pm 173 & 5 \\ \text { MK-801+Veh } & 1,377 \pm 129 & 5 \\ \text { Clozapine (5.0)+Veh } & 137 \pm 37 & 5 \\ \text { Clozapine (5.0)+MK-801 } & 907 \pm 160 & 6 \\ \text { Experiment 2 } & & \\ \text { A Veh-Veh } & 349 \pm 44 & 8 \\ \text { MK-801+Veh } & 1,124 \pm 224 & 9 \\ \text { SB 271046 (6.0)+Veh } & 676 \pm 175 & 7 \\ \text { SB 271046 (6.0)+MK-801 } & 1,275 \pm 156 & 9 \\ \text { SB 271046 (9.0)+Veh } & 396 \pm 85 & 7 \\ \text { SB 271046 (9.0)+MK-801 } & 935 \pm 164 & 9\end{array}$

B Veh-Veh

$310 \pm 79 \quad 10$

MK-801+Veh

$784 \pm 75 \quad 10$

SB 399885 (3.0)+Veh

SB 399885 (3.0)+MK-801

$542 \pm 95 \quad 6$

$725 \pm 117 \quad 6$

$605 \pm 126 \quad 5$

$1,502 \pm 152 \quad 8$

SB 399885 (6.0)+MK-801

Experiment 3

$\mathrm{A}$ Veh+Veh

MK-801+Veh

Clozapine (2.5)+Veh

Clozapine (2.5)+MK-801

Clozapine (5.0) + Veh

Clozapine (5.0)+MK-801

$275.0 \pm 48 \quad 9$

$1,006 \pm 106 \quad 9$

$144.0 \pm 25 \quad 8$

$680 \pm 120 \quad 8$

$223 \pm 69 \quad 7$

$928 \pm 139 \quad 9$

B Veh+Veh

$490 \pm 154 \quad 7$

MK-801+Veh

Clozapine (2.5)+Veh

Clozapine (2.5)+MK-801

$1,879 \pm 382 \quad 7$

$243 \pm 49 \quad 8$

$680 \pm 120 \quad 8$

$327 \pm 91 \quad 7$

$882 \pm 76 \quad 9$

$310 \pm 177 \quad 4$

$655 \pm 82 \quad 9$

Clozapine (2.5)+SB 271046+MK-801

Experiment 4

$\mathrm{A}$ Veh+Veh

$574 \pm 212 \quad 6$

MK-801+Veh

Haloperidol $(0.1)+$ Veh

Haloperidol (0.1)+MK-801

$1,868 \pm 367 \quad 6$

$1,697 \pm 474 \quad 6$

$1,537 \pm 478 \quad 6$

Haloperidol (0.2) + Veh

$986 \pm 113 \quad 5$ 
Table 1 (continued)

\begin{tabular}{|c|c|c|}
\hline Drug/dose (mg/kg) & Startle & $N$ \\
\hline Haloperidol (0.2)+MK-801 & $1,671 \pm 206$ & 5 \\
\hline B Veh+Veh & $845 \pm 283$ & 6 \\
\hline MK-801+Veh & $1,029 \pm 213$ & 5 \\
\hline Haloperidol $(0.1)+$ Veh & $564 \pm 149$ & 6 \\
\hline Haloperidol (0.1)+MK-801 & $1,304 \pm 296$ & 5 \\
\hline SB $271046(6)+$ Veh & $1,087 \pm 293$ & 6 \\
\hline SB $271046(6)+M K-801$ & $889 \pm 188$ & 8 \\
\hline Haloperidol (0.1)+SB 271046(6.0) & $664 \pm 138$ & 5 \\
\hline Haloperidol (0.1)+SB 271046+MK-801 & $1,290 \pm 206$ & 5 \\
\hline \multicolumn{3}{|l|}{ Experiment 5} \\
\hline $\mathrm{A}$ Veh+Veh & $463 \pm 88$ & 6 \\
\hline MK-801+Veh & $947 \pm 102$ & 6 \\
\hline Risp $(0.25)+$ Veh & $454 \pm 86$ & 5 \\
\hline Risp (0.25)+MK-801 & $1,077 \pm 152$ & 8 \\
\hline Risp (0.5)+Veh & $380 \pm 135$ & 5 \\
\hline Risp (0.5)+MK-801 & $868 \pm 125$ & 11 \\
\hline Risp (1.0)+Veh & $416 \pm 109$ & 5 \\
\hline Risp (1.0)+MK-801 & $920 \pm 243$ & 9 \\
\hline B Veh+Veh & $438 \pm 53$ & 9 \\
\hline SB $271046(6)+$ Veh & $396 \pm 59$ & 6 \\
\hline Risp (1.0)+Veh & $275 \pm 82$ & 8 \\
\hline Risp (1.0)+SB 271046 (6) & $92 \pm 15$ & 8 \\
\hline MK-801+Veh & $914 \pm 193$ & 7 \\
\hline SB $271046(6)+\mathrm{MK}-801$ & $978 \pm 148$ & 7 \\
\hline Risp (1.0)+MK-801 & $728 \pm 75$ & 13 \\
\hline Risp (1.0)+SB 271046 (6)+MK-801 & $697 \pm 139$ & 7 \\
\hline $\mathrm{C}$ Veh+Veh & $300 \pm 56$ & 13 \\
\hline SB 399885 (3)+Veh & $556 \pm 97$ & 6 \\
\hline Risp (1.0)+Veh & $341 \pm 72$ & 9 \\
\hline Risp (1.0)+SB 399885 (3) & $266 \pm 52$ & 8 \\
\hline MK-801+Veh & $449 \pm 67$ & 11 \\
\hline SB 399885 (3)+MK-801 & $659 \pm 93$ & 7 \\
\hline Risp (1.0)+MK-801 & $719 \pm 123$ & 8 \\
\hline Risp (1.0)+SB 399885 (3)+MK-801 & $537 \pm 52$ & 13 \\
\hline \multicolumn{3}{|l|}{ Experiment 6} \\
\hline $\mathrm{A}$ Veh+Veh & $459 \pm 70$ & 8 \\
\hline MK-801+Veh & $1,726 \pm 237$ & 8 \\
\hline M100907 (0.5)+Veh & $333 \pm 49$ & 8 \\
\hline M100907 (0.5)+MK-801 & $1,002 \pm 183$ & 6 \\
\hline M100907 (1.0)+Veh & $566 \pm 93$ & 8 \\
\hline M100907 (1.0)+MK-801 & $2,019 \pm 325$ & 8 \\
\hline B Veh+Veh & $725 \pm 133$ & 9 \\
\hline MK-801+Veh & $1,074 \pm 109$ & 9 \\
\hline M100907 (0.5)+Veh & $222 \pm 46$ & 7 \\
\hline M100907 (0.5)+MK-801 & $934 \pm 143$ & 8 \\
\hline
\end{tabular}

Table 1 (continued)

\begin{tabular}{lll}
\hline Drug/dose (mg/kg) & Startle & $N$ \\
\hline SB 399885 (3)+Veh & $396 \pm 85$ & 7 \\
SB 399885 (3)+MK-801 & $916 \pm 162$ & 9 \\
M100907 (0.5)+SB 399885 (3.0) & $452 \pm 95$ & 5 \\
M100907 (0.5)+SB 399885+MK-801 & $1,162 \pm 312$ & 9 \\
& & \\
C Veh+Veh & $333 \pm 43$ & 10 \\
MK-801+Veh & $746 \pm 77$ & 10 \\
M100907 (0.5)+Veh & $463 \pm 75$ & 12 \\
M100907 (0.5)+MK-801 & $1,781 \pm 299$ & 10 \\
SB 399885 (3)+Veh & $509 \pm 79$ & 6 \\
SB 399885 (3)+MK-801 & $638 \pm 96$ & 5 \\
M100907 (0.5)+SB 399885 (3.0) & $258 \pm 32$ & 4 \\
M100907 (0.5)+SB 399885+MK-801 & $552 \pm 71$ & 6 \\
\hline
\end{tabular}

The results are presented as the means \pm S.E.M. The numbers in parentheses indicate the doses used

Experiment 2: effects of 5-HT6 receptor antagonists SB 271046 and SB 399885 on the PPI deficit evoked by MK-801

MK-801 significantly reduced the PPI, and this deficit was not counteracted by pretreatment with the 5-HT6 receptor antagonist SB 271046 (Fig. 2a). An ANOVA revealed the significant effect of MK-801 $(F(1,43)=27.647 ; P<0.001)$, but there was no significant effect resulting from SB 271046 treatment, nor was there a significant interaction between the MK-801 and SB 271046 treatments. There was a significant overall effect of prepulse intensity $(F(2,86)=6.196 ; P<0.01)$ and no significant interactions of the factors and stimuli intensity. As shown in Table 1, MK-801 significantly elevated the startle amplitude $(F(1,43)=23.353 ; P<0.001)$; however, there was no significant effect of SB 271046, and no significant interaction between MK-801 and SB 271046 treatment was found on this measure.

Similarly, the MK-801-induced PPI deficit was not counteracted by pretreatment with the 5-HT6 receptor antagonist SB 399885 (Fig. 2b). An ANOVA revealed the significant effect of MK-801 $(F(1,39)=22.251 ; P<0.001)$, but there was no significant effect due to SB 399885 treatment nor was there a significant interaction between the MK- 801 and SB 399885 treatments. There was a significant overall effect of the prepulse intensity $(F(2,78)=12.095 ; P<0.001)$ and insignificant interactions of the factors and stimuli intensity. As shown in Table 1, MK-801 significantly elevated the startle amplitude $(F(1,39)=30.838 ; P<0.001)$. Treatment with SB 399885 also had a significant effect on the startle amplitude $(F(2,39)=12.494 ; P<0.001)$, and a significant interaction between the MK- 801 and SB 399885 treatments was observed $(F(2,39)=4.630 ; P<0.05)$. 


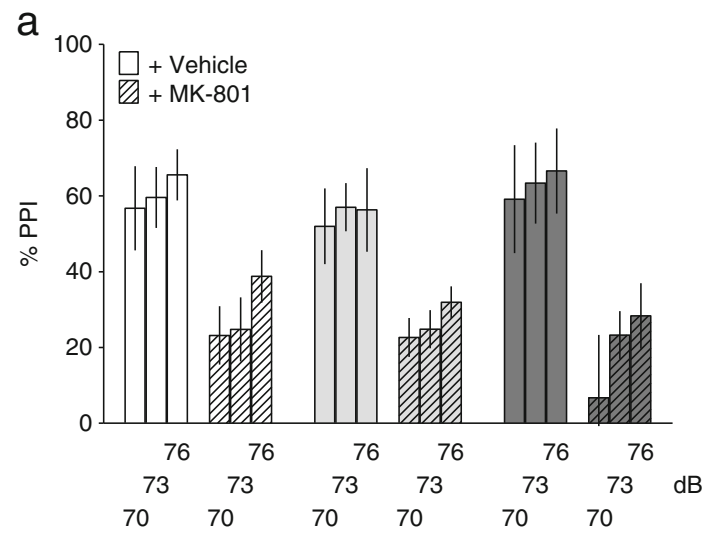

$\mathrm{SB} 271046(\mathrm{mg} / \mathrm{kg}) \quad-0-6-6-9-$

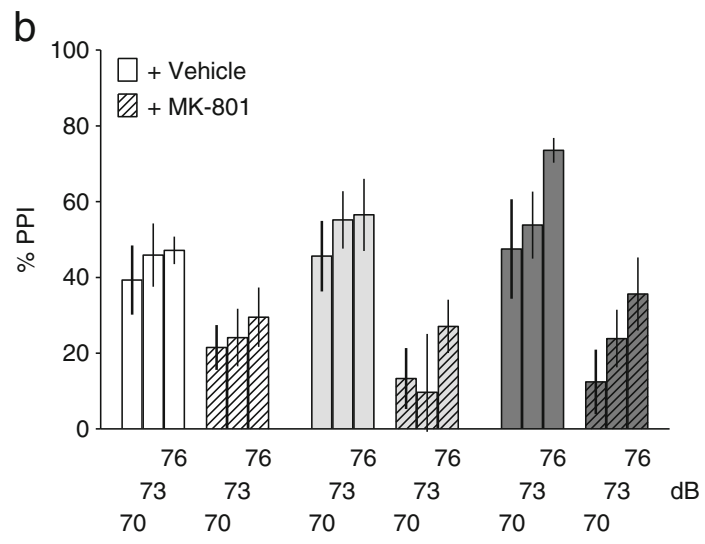

$\mathrm{SB} 399885(\mathrm{mg} / \mathrm{kg})-0-3-5-6-$

Fig. 2 The lack of effects of the 5-HT6 receptor antagonists a SB $271046(6$ and $9 \mathrm{mg} / \mathrm{kg}$ ) and b SB 399885 on MK-801 (0.1 mg/kg)induced PPI deficit

Experiment 3: effects of clozapine alone and in combination with SB 271046 on the PPI deficits evoked by MK-801

An ANOVA revealed the significant main effect of the MK801 treatment $(F(1,44)=9.677 ; P<0.01)$ and the interaction between the MK-801 and clozapine treatments $(F(2,44)=$ $3.754, P<0.05$, Fig. 3a). There was a significant overall effect of the prepulse intensity $(F(2,88)=11.899 ; P<0.01)$, but no interactions of the factors with the stimuli intensity were observed. The post hoc comparisons revealed that treatment with MK-801 and clozapine $(5 \mathrm{mg} / \mathrm{kg}$ ) significantly elevated the PPI compared with the MK-801 and the vehicle-treated group. Clozapine did not change the PPI in the vehicle-treated group. While MK-801 elevated the startle amplitude $(F(1,44)$ $=68.839 ; P<0.01$, Table 1), there was an insignificant effect of clozapine and no significant interaction between MK-801 and clozapine treatment on this measure.

Figure $3 \mathrm{~b}$ shows the effects of a combined treatment of clozapine and SB 271046. An ANOVA revealed the

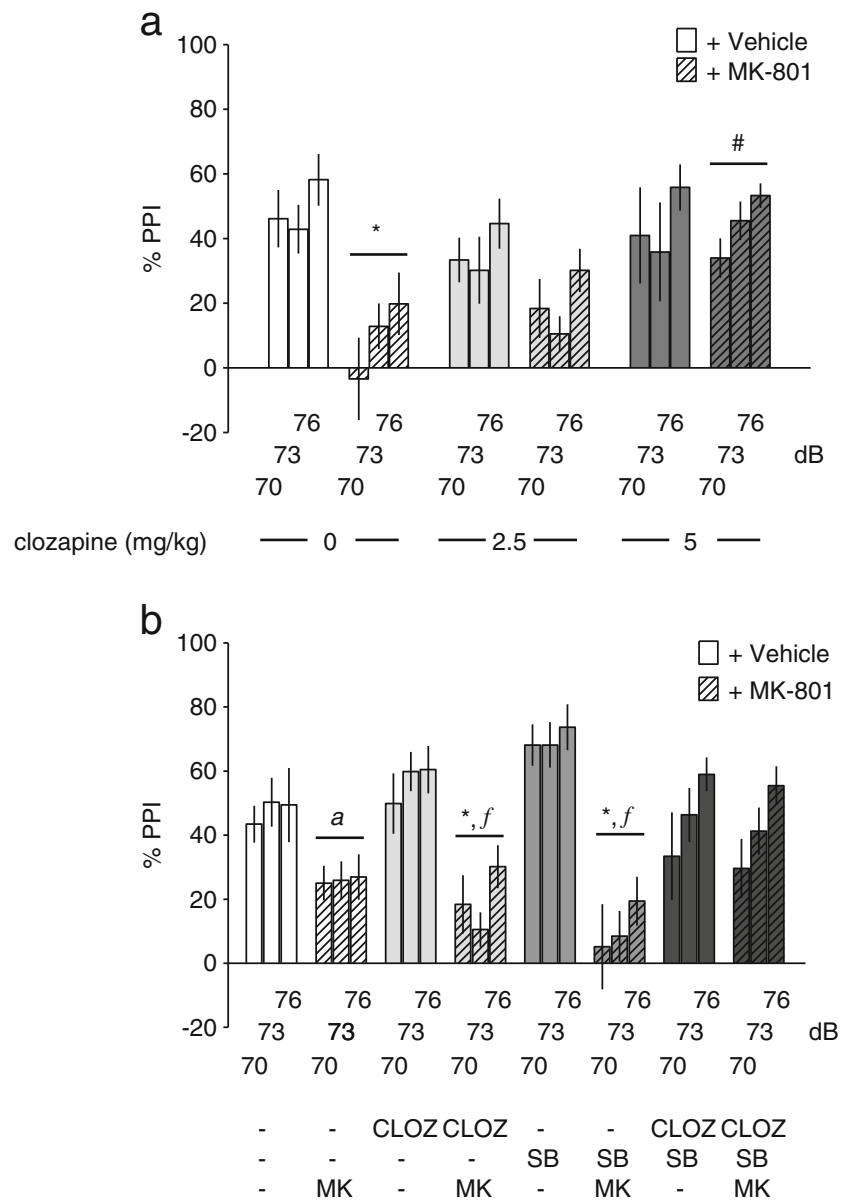

Fig. 3 a Attenuating effects of clozapine (5, but not $2.5 \mathrm{mg} / \mathrm{kg}$ ) administered alone and $\mathbf{b}$ attenuating effect of the co-administration of clozapine $(2.5 \mathrm{mg} / \mathrm{kg})$ with SB $271046(6 \mathrm{mg} / \mathrm{kg})$ on MK-801 $(0.1 \mathrm{mg} / \mathrm{kg})-$ induced PPI deficits. Symbols: ${ }^{*} P<0.05(a P=0.06)$ versus the vehicle; $\# P<0.05$ versus the MK- 801 treatment; $\int P<0.05$ versus the clozapine+ SB 271046+MK-801 treatment

significant main effect of the MK-801 treatment $(F(1,51)=$ $33.583 ; P<0.01)$, and the interaction among MK-801, clozapine, and SB 271046 treatments $(F(1,51)=11.101$; $P<0.05)$. MK-801 near-significantly $(P=0.06)$ reduced the PPI compared with the vehicle treatment. Combined administration of inactive doses of clozapine $(2.5 \mathrm{mg} / \mathrm{kg})$ and SB $271046(6 \mathrm{mg} / \mathrm{kg})$ restored the PPI deficit evoked by MK-801, compared to the clozapine+MK-801 and compared to the SB $271046+\mathrm{MK}-801$ groups. There was also an overall effect of the prepulse intensity $(F(2,102)=12.923 ; P<0.01)$, but no interaction between this and other factors was observed. MK-801 significantly elevated the startle amplitude $(F(1,51)=33.913 ; P<0.01$, Table 1). A significant interaction between the MK-801 and clozapine treatments $(F(1,51)=6.161 ; P<0.05)$ suggests that clozapine $(2.5 \mathrm{mg} / \mathrm{kg})$ attenuated the MK-801-enhanced startle amplitude. 


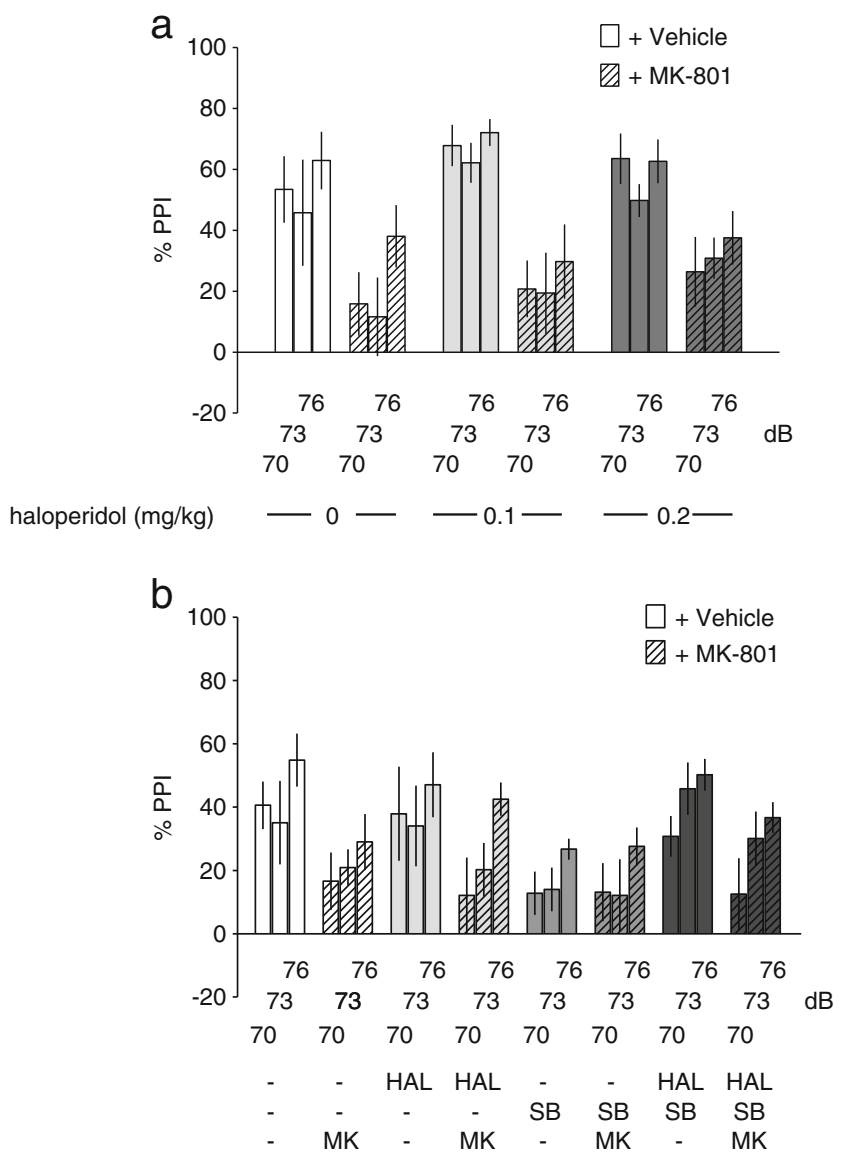

Fig. 4 Lack of effects of a haloperidol ( 0.1 and $0.2 \mathrm{mg} / \mathrm{kg}$ ) given alone and of b co-administration of haloperidol $(0.1 \mathrm{mg} / \mathrm{kg})$ and SB 271046 $(6 \mathrm{mg} / \mathrm{kg})$ on MK-801 $(0.1 \mathrm{mg} / \mathrm{kg})$-induced PPI deficits

Experiment 4: effects of haloperidol alone and in combination with SB 271046 on the PPI deficits evoked by MK-801

MK-801 significantly reduced PPI, but in contrast to clozapine, this deficit was not reversed by either dose of haloperidol (Fig. 4a). An ANOVA revealed the significant main effect of MK-801 $(F(1,28)=19.191 ; P<0.01)$ and the insignificant effect of haloperidol and the insignificant interaction between MK-801 and haloperidol. There was a significant overall effect of prepulse intensity $(F(2,56)=14.11 ; P<0.01)$, and no significant interactions of the factors and stimuli intensity were observed. While MK-801 significantly elevated the startle amplitude $(F(1,28)=4.326 ; P<0.05)$, haloperidol did not have a significant effect, and there was no significant interaction between MK-801 and haloperidol treatment on this measure.

Co-administration of haloperidol $(0.1 \mathrm{mg} / \mathrm{kg})$ and SB $271046(6 \mathrm{mg} / \mathrm{kg})$ produced no effect on the PPI deficit evoked by MK-801 (Fig. 4b). An ANOVA demonstrated a significant effect of MK-801 $(F(1,38)=6.675 ; P<0.05)$, but there was no significant interaction between MK-801, haloperidol, and SB 271046. There was an overall effect on the prepulse intensity $(F(2,76)=14.124, P<0.01)$, but no interaction was observed among the MK-801, haloperidol, SB 271046, and the prepulse intensity factors. MK- 801 significantly elevated the startle amplitude $(F(1,38)=4.218 ; P<$ 0.05 , Table 1$)$, but there were no interactions among the MK801, haloperidol, and SB 271046 factors on this measure.

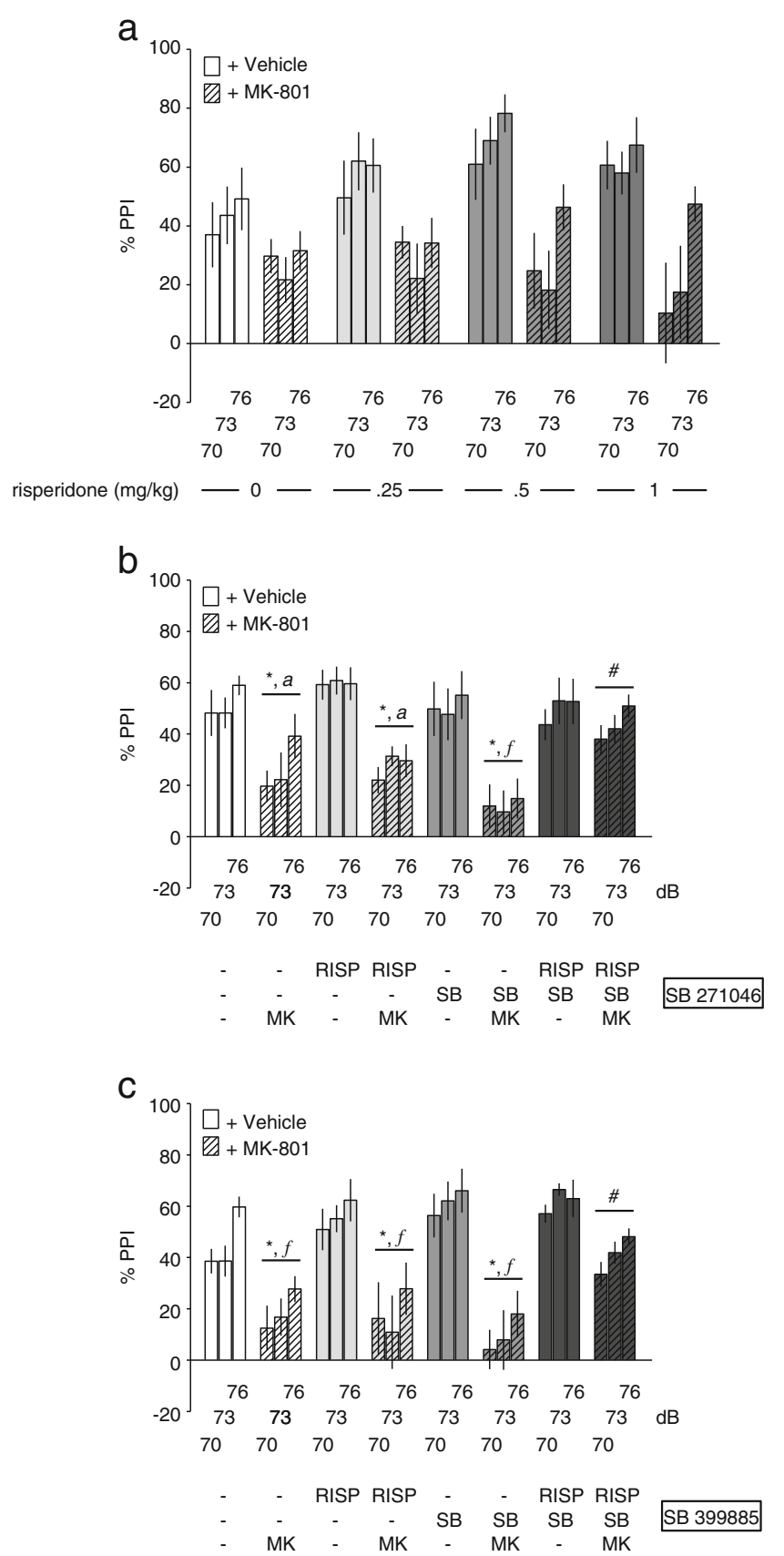

Fig. 5 a Lack of effect of risperidone given alone and the attenuating effect of the combined administration of risperidone $(1 \mathrm{mg} / \mathrm{kg})$ with $\mathbf{b} \mathrm{SB}$ $271046(6 \mathrm{mg} / \mathrm{kg})$ and c SB $399885(3 \mathrm{mg} / \mathrm{kg})$ on MK-801 $(0.1 \mathrm{mg} / \mathrm{kg})-$ induced PPI deficits. Symbols: $* P<0.05$ versus the vehicle; $\# P=0.07$ (b) and $P<0.05$ (c) versus the MK-801 treatment; $\int P<0.05(a P=0.06-0.07)$ versus the risperidone + SB 271046 or SB $399885+$ MK- 801 treatment 
Experiment 5: effects of risperidone alone and in combination with SB 271046 or with SB 399885 on the PPI deficits evoked by $\mathrm{MK}-801$

Risperidone at doses of $0.25-1 \mathrm{mg} / \mathrm{kg}$ did not attenuate the PPI deficit in MK-801-treated rats (Fig. 5a). An ANOVA revealed a significant effect of MK-801 $(F(1,47)=17.017 ; P<0.001)$ but an insignificant interaction between the MK-801 and risperidone treatments. There was a significant overall effect of the prepulse intensity $(F(2,94)=7.509 ; P<0.001)$ but an insignificant interaction between the prepulse intensity and other factors. While MK-801 significantly elevated the startle amplitude $(F(1,47)=19.232 ; P<0.01)$, the interaction between MK-801 and risperidone treatments was not significant (Table 1).

Figure $5 \mathrm{~b}$ shows the effects of a combined treatment with $1 \mathrm{mg} / \mathrm{kg}$ risperidone and $6 \mathrm{mg} / \mathrm{kg}$ SB 271046. An ANOVA revealed the significant main effect of the MK-801 treatment $(F(1,57)=35.619 ; P<0.001)$ and the risperidone treatment $(F(1,57)=5.226 ; P<0.05)$, as well as a significant interaction among the MK-801, risperidone, and SB 271046 treatments $(F(1,57)=5.503 ; P<0.05)$. There was also a significant overall effect of the prepulse intensity $(F(2,114)=6.310 ; P<0.01)$ but no significant interactions of the factors and stimuli intensity. Combined administration of an inactive dose of risperidone and SB 271046 restored the PPI deficit evoked by MK801, compared to SB 271046+MK-801 $(P<0.001)$ and, less significantly, to the risperidone $+\mathrm{MK}-801(P=0.06)$ groups; however, this effect was not significant when compared with the vehicle $+\mathrm{MK}-801$ group $(P=0.07)$. While MK-801 significantly elevated $(F(1,57)=50.296 ; P<0.001)$ and risperidone significantly reduced the startle amplitude $(F(1,57)=9.794$; $P<0.01)$, other factors and interactions of this measure were insignificant (Table 1).

Figure $5 \mathrm{c}$ shows the effects of a combined treatment with $1 \mathrm{mg} / \mathrm{kg}$ risperidone and $3 \mathrm{mg} / \mathrm{kg} \mathrm{SB}$ 399885. An ANOVA revealed the significant main effect of the MK-801 treatment $(F(1,67)=51.178 ; P<0.001)$ and the risperidone treatment $(F(1,67)=4.724 ; P<0.05)$, as well as a significant interaction among the MK-801, risperidone, and SB 399885 treatments $(F(1,67)=4.719 ; P<0.05)$. There was also a significant overall effect of the prepulse intensity $(F(2,134)=22.675$; $P<0.01)$ and an interaction between the prepulse intensity and SB 399885 treatment $(F(2,134)=3.153 ; P<0.05)$; the other factors did not interact with the prepulse intensity. Combined administration of an inactive dose of risperidone and SB 399885 restored the PPI deficit evoked by MK-801 compared to the SB 399885+MK-801 $(P<0.001)$, the risperidone+ MK-801 $(P<0.01)$, and the vehicle+MK-801 $(P<0.01)$ groups. MK-801 significantly elevated the startle amplitude $(F(1,67)=17.113 ; P<0.001)$, and there was a significant interaction between the risperidone and SB 399885 treatments $(F(1,67)=10.977 ; P<0.01)$; however, the other factors and interactions of this measure were insignificant (Table 1).
Experiment 6: effects of 5-HT2A receptor antagonist M100907 alone and in combination with SB 271046 and with SB 399885 on the PPI deficits evoked by MK-801

The 5-HT2A receptor antagonist M100907 at doses of 0.5 and $1 \mathrm{mg} / \mathrm{kg}$ did not attenuate the PPI deficit in MK-801-treated rats (Fig. 6a). An ANOVA revealed a significant effect of MK$801(F(1,40)=41.819 ; P<0.001)$ but an insignificant

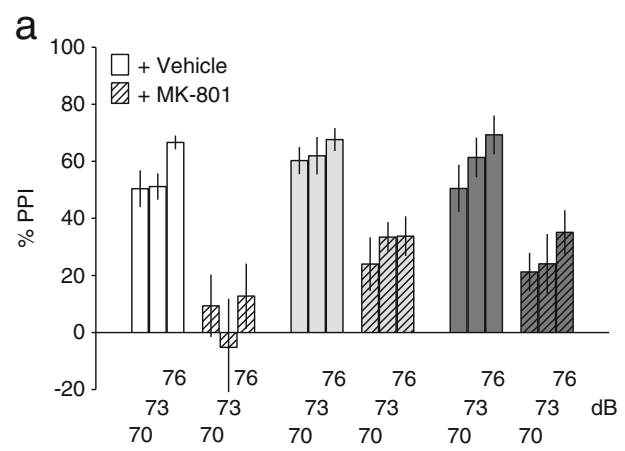

M100907 (mg/kg) - $0--0.5--1-$
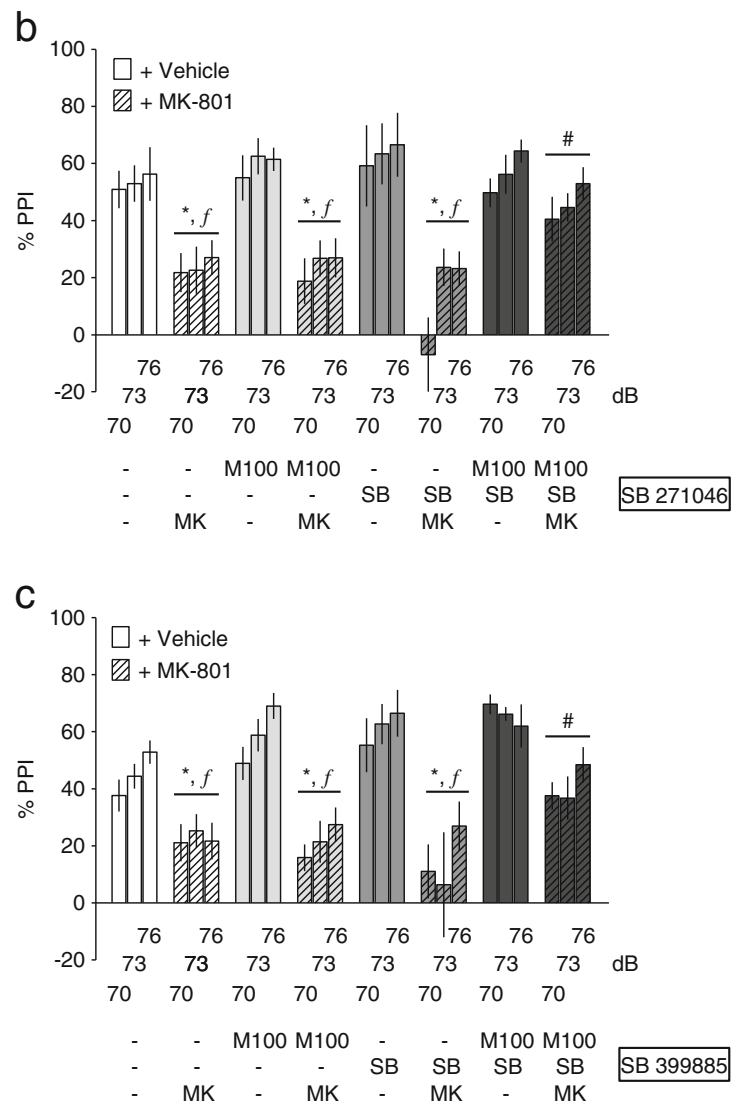

Fig. 6 a Lack of effect of the 5-HT2A antagonist M100907 (0.5 and $1 \mathrm{mg} / \mathrm{kg}$ ) given alone and the attenuating effect of combined administration of M100907 $(0.5 \mathrm{mg} / \mathrm{kg})$ with b SB $271046(6 \mathrm{mg} / \mathrm{kg})$ and $\mathbf{c}$ SB $399885(3 \mathrm{mg} / \mathrm{kg})$ on MK-801 (0.1 mg/kg)-induced PPI deficits. Symbols: ${ }^{*} P<0.05$ versus the vehicle; $\# P<0.05$ versus the MK-801 treatment; $\int P<0.05$ versus the M100907+SB 271046+MK-801 treatment 
interaction between the MK-801 and M100907 treatments. There was a significant overall effect of the prepulse intensity $(F(2,80)=9.235 ; P<0.001)$ but an insignificant interaction among the prepulse intensity and other factors. While MK801 significantly elevated the startle amplitude $(F(1,40)=$ 52.924; $P<0.01)$, the interaction between the MK- 801 and M100907 treatments was insignificant.

Figure $6 \mathrm{~b}$ shows the effects of a combined treatment with lower doses of M100907 and SB 271046. An ANOVA showed the significant main effect of MK-801 treatment $(F(1,55)=41.591 ; P<0.001)$ and a significant interaction between the MK-801, M100907, and SB 271046 treatments $(F(1,55)=5.303 ; P<0.05)$. Combined administration of inactive doses of M100907 $(0.5 \mathrm{mg} / \mathrm{kg})$ and SB $271046(6 \mathrm{mg} / \mathrm{kg})$ restored the PPI deficit evoked by MK-801 compared to the M100907+MK-801, the SB 271046+MK-801, and the vehicle + MK- 801 groups. While MK-801 significantly elevated the startle amplitude $(F(1,55)=19.543 ; P<0.01)$, other factors and interactions of this measure were insignificant (Table 1).

Figure $6 \mathrm{c}$ shows the effects of combined treatment with lower doses of M100907 and SB 399885. An ANOVA showed the significant main effect of MK-801 treatment $(F(1,55)=$ 59.740; $P<0.001)$, the significant main effect of SB 399885 treatment $(F(1,55)=4.236 ; P<0.05)$, the significant main effect of M100907 treatment $(F(1,55)=6.527 ; P<0.05)$, and most importantly, the significant interaction between the MK-801, M100907, and SB 399885 treatments $(F(1,55)=4.666$; $P<0.05)$. Combined administration of inactive doses of M100907 $(0.5 \mathrm{mg} / \mathrm{kg})$ and SB $399885(3 \mathrm{mg} / \mathrm{kg})$ restored the PPI deficit evoked by MK-801, compared to the M100907+ MK-801, the SB 399885+MK-801, and the vehicle+MK-801 groups. MK-801 significantly elevated the startle amplitude $(F(1,55)=21.749 ; P<0.001)$, but the interaction among all three treatments was insignificant (Table 1).

\section{Discussion}

The major findings of the present study can be summarized as follows: while 5-HT6 and 5-HT2A receptor antagonists, as well as haloperidol and risperidone, did not affect the PPI deficit produced by MK-801, clozapine dose-dependently ameliorated it. However, co-administration of the 5-HT6 antagonists with clozapine, risperidone, or the 5-HT2A antagonist, but not haloperidol, reversed the MK-801-induced PPI deficit.

Our results regarding haloperidol replicate previous findings that demonstrated that "typical" antipsychotics are not effective in restoring the PPI deficits induced by NMDA receptor antagonist administration (Keith et al. 1991). Clozapine produces inconsistent effects on the disruptive effects of MK-801. While some studies report that pretreatment with clozapine reversed the deficits produced by MK-801 (Bakshi et al. 1994; Bubenikova et al. 2005), this effect was not observed by others
(Hoffman et al. 1993; Varty and Higgins 1995; Bast et al. 2000; Levin et al. 2005; Gururajan et al. 2011). This inconsistency could be due to a number of the methodological issues. First, it is possible that there is a rather short time window for clozapine to ameliorate the PPI deficits evoked by MK-801, and therefore in certain experimental settings, this effect could not be detectable. For example, the reversing effect of clozapine was observed when a relatively short testing protocol was employed (5 repetitions $\times 4$ trial types; Bubenikova et al. 2005). In another study, a similar ameliorative effect of clozapine was detected during the second half of a long session that totaled 62 trials (Bakshi et al. 1994). Because our data replicated these observations (Fig. 1), in the present study, a protocol consisting of 4 repetitions of each trial type was used. Second, the PPI testing procedure could produce stress, which might interfere with the animals' response to the stimuli and might mask the ameliorative effects of clozapine on the MK-801-evoked deficit. To overcome this problem, we conducted two habituation sessions, which directly preceded the drug test session.

The efficacy of the antipsychotic drugs has been attributed to their antagonistic activity at several receptor types (e.g., dopamine D2, D3, serotonin 5-HT2A, 5-HT2C, and 5-HT6). Clozapine exhibits a high affinity for 5 -HT6 receptors $(\mathrm{Ki}=12.88 \mathrm{nM}$; Boess et al. 1997) with a selectivity about 5-fold over D2 receptors and more than 10 -fold over D3 receptors. Among serotonin receptors, the affinity of clozapine for 5-HT2A receptors $(\mathrm{Ki}=10.96 \mathrm{nM})$ is comparable to its affinity for 5 -HT6 receptors, which is about 3-fold higher than its affinity for 5HT2C receptors ( $\mathrm{Ki}=29 \mathrm{nM}$; PDSP certified data). To investigate the involvement of the serotonin type-6 receptors in mediating the reversal of the MK-801-induced PPI deficit, we used the potent (Ki 0.7 nM) 5-HT6 receptor antagonists SB 271046 and SB 399885 (Upton et al. 2008). To investigate the role of the 5-HT2A receptors, we used the potent $(\mathrm{Ki}=1.92 \mathrm{nM}$; PDSP certified data) 5-HT2A receptor antagonist M100907.

The administration of SB 271046 and SB 399885 (Fig. 2) consistently failed to antagonize the PPI disruptions evoked by MK- 801 . To date, there have been few studies on prepulse inhibition disrupted by NMDA receptor antagonists, and all these studies have reported negative results with the selective 5-HT6 antagonists SB 271046, Ro 04-6790, Ro 65-7199, and Ro 4368554 (Pouzet et al. 2002; Leng et al. 2003; Schreiber et al. 2007; Gravius et al. 2011). In two other studies, the 5HT6 receptor antagonists SB 271046 and Ro 4368554 reversed the PPI deficits evoked by amphetamine and apomorphine, respectively (Pouzet et al. 2002; Mitchell and Neumaier 2008). Thus, as expected, our study replicated the negative findings in the model of PPI disruptions evoked by NMDA receptor antagonists. Similarly, administration of the 5-HT2A receptor antagonist did not antagonize the PPI disruptions produced by MK-801 (Fig. 6a), which confirms earlier reports (Bakshi et al. 1994; Swerdlow et al. 1996). However, these and our results are contrasted by the finding that $1 \mathrm{mg} / \mathrm{kg}$ 
M100907 antagonized the PPI disruption induced by MK-801 (Varty et al. 1999). It is likely that differences in the experimental protocols were responsible for these discrepancies.

While administration of SB 271046, SB 399885, or M100907 alone did not affect the MK-801-induced PPI deficit, the combination of either 5-HT6 antagonist with the 5HT2A antagonist attenuated it (Fig. 6) in a manner comparable to clozapine. The ability of a combined treatment with 5HT2A and 5-HT6 antagonists to reduce the disruptive effects of MK-801 may suggest that inhibition of these serotonergic receptors may sufficiently explain the similar ameliorating effects of clozapine. This could be supported by the observation that 5-HT6 receptor antagonism potentiated the action of an ineffective dose of clozapine (Fig. 3b). This idea is further supported by the results of the combined administration of SB 271046 or SB 399885 and risperidone, an antipsychotic that displays high affinities for the $\mathrm{D} 2(\mathrm{Ki} \sim 2 \mathrm{nM})$ and 5-HT2A $(\mathrm{Ki}<1 \mathrm{nM})$ receptors, but not the 5-HT6 $(\mathrm{Ki} \sim 2,000 \mathrm{nM})$ receptors (PDSP certified data).

The 5-HT6 receptors are distributed most densely within the medial prefrontal cortex, the hippocampus, and the basal ganglia (Gerard et al. 1997). These brain regions are also a part of the circuitry involved in the regulation of PPI (Swerdlow et al. 2001). It was also demonstrated that $\left[{ }^{3} \mathrm{H}\right]$ clozapine binding resembles the distribution of 5-HT6 receptors in the brain (Glatt et al. 1995). Moreover, chronic administration of clozapine decreased 5-HT6 receptor expression in the hippocampus (Frederick and Meador-Woodruff 1999). Therefore, the functional interaction between clozapine and 5-HT6 receptors may support our behavioral observation, suggesting the involvement of 5HT6 receptor antagonism in the antipsychotic-like action of clozapine in restoring PPI deficits. In contrast, SB 271046 combined with the "typical" antipsychotic haloperidol, regarded as a preferential dopamine $\mathrm{D} 2$ antagonist $(\mathrm{Ki}=0.45 \mathrm{nM}$; PDSP certified data), was ineffective at inhibiting PPI deficits (Fig. 4b). This suggests that the mixed D2/5-HT6 antagonistic effect of antipsychotics may not be of significant importance for the restoration of PPI impairments.

IThe efficacy of "atypical" antipsychotics in reversing the PPI deficits induced by NMDA receptor blockade has been attributed to the serotonin/glutamate interaction, which is mediated via the 5-HT2A receptors (Varty and Higgins 1995; Varty et al. 1999). This concept has been supported by a number of studies, which show that drugs displaying 5-HT2A receptor antagonistic properties reverse NMDA receptor antagonist-induced PPI deficits and facilitate glutamate neurotransmission in the cerebral cortex (Varty and Higgins 1995; Arvanov and Wang 1998; Varty et al. 1999). Evidence suggests that 5-HT6 receptors may also control glutamatergic neurotransmission in the brain. For instance, in microdialysis studies, the 5-HT6 antagonist SB 271046-induced robust increases in glutamate and aspartate concentrations in the frontal cortex (Dawson et al. 2001; Mork et al. 2009). A massive enhancement of cortical glutamatergic neurotransmission in freely moving rats was also observed following injection with a high, but not a lower, dose of clozapine (Daly and Moghaddam 1993). The prefrontal cortex is a key structure within a neuronal circuit responsible for the PPI disruptive effect of NMDA receptor antagonists (Schwabe and Koch 2004; Klamer et al. 2011). Therefore, the additive effect of the combined administration of 5-HT6 antagonist(s) with clozapine, risperidone, or M100907 in alleviating PPI deficits is likely explained by the amplification of cortical glutamate neurotransmission following 5-HT6 receptor blockade. It can be hypothesized that the 5-HT6 component that "repairs" cortical function could also be a key factor in the mechanism of the antipsychotic action of "atypical" drugs.

An alternative explanation of the present results involves the central cholinergic functions. It has been demonstrated that compounds that exert agonistic effects at muscarinic receptors exhibit anti-psychotic-like properties (Maehara et al. 2008). Moreover, it has been reported that the clozapine metabolite N-desmethylclozapine (NDMC), which exhibits partial agonistic activity at the muscarinic M1 receptor, reversed the disruption of PPI caused by ketamine (Maehara et al. 2011). The authors suggested that NDMC, which is present in high concentrations in both humans and rats, might contribute to the antipsychotic effects of clozapine via the activation of the muscarinic receptors (Maehara et al. 2011). Given that 5-HT6 receptor antagonists might exert similar choline-mimetic effects (Riemer et al. 2003), it is possible that the enhancement of the clozapine action following SB 271046 co-administration can be attributed to its actions in the cholinergic pathways.

Further research is needed to clarify the neuronal circuits that contribute to the observed effects of 5-HT6 receptor antagonism in alleviating the prepulse deficits. For instance, it has been demonstrated that 5-HT6 receptors are expressed on GABAergic interneurons in the striatum (Gerard et al. 1997) and thus regulate other neurotransmitter systems through the modulation of GABAergic output. Moreover, 5-HT6 and 5HT2A receptors may control the activity of dopaminergic neurons in mesolimbic and mesocortical projections. It has been found that 5-HT6 receptor antagonists do not influence brain dopamine levels by itself, but combined 5-HT6/D2 and 5-HT6/5-HT2A antagonism can potentiate a dopamine efflux in the cerebral cortex ( $\mathrm{Li}$ et al. 2007); likewise, a joint administration of amphetamine and a 5-HT6 receptor antagonist also potentiated the dopamine levels in the striatum (Dawson et al. 2003). Therefore, differential effects of 5-HT6 receptor antagonism alone versus combined 5-HT6/5-HT2A antagonism and the involvement of other receptors and neurotransmitter systems may contribute to the effects observed in our study.

There are several limitations of the present study. As in every pharmacological research study involving the administration of two or three compounds, we cannot exclude the effects of the pharmacokinetic interactions. Among the 5-HT6 antagonists, the SB 271046 compound is most frequently used 
in behavioral studies and is $>200$-fold more selective for the 5 HT6 receptors than for 23-85 other receptors investigated; however, this compound displays a relatively poor brain permeability (brain/plasma concentration ratio of $0.05: 1$ ). For these reasons, the effects of the combined treatment of the 5HT6 receptor antagonist with risperidone or M100907 on prepulse inhibition were also assessed using another 5-HT6 antagonist, SB 399885, which has been shown to have a better brain/plasma concentration ratio (0.15:1; Upton et al. 2008).

The limited clinical data on the effects of combined treatment of 5-HT6 receptor antagonist and risperidone are equivocal. A public company release from Lundbeck (2008) entitled "Efficacy study exploring the effect of Lu AE58054 as augmentation therapy in patients with schizophrenia" is listed under "nonapproved indications," and Arnt and Olsen describing these clinical results have noted the lack of improved outcome on the psychosis ratings (Borsini 2011, p. 146). However, there could be a number of reasons for the failure of the clinical trial, and/or, it cannot be excluded that the positive effects observed in the preclinical prepulse inhibition test do not always translate into clinical efficacy. More recently, Morozova et al. studied the effects of risperidone given with another 5-HT6 antagonist and antihistamine drug, dimebolin (Dimebon ${ }^{\mathrm{TM}}$ ), in schizophrenic patients (Morozova et al. 2012). An earlier study of Schaffhauser et al. (2009) have demonstrated that dimebolin displays a decent affinity for human $(\mathrm{Ki}=26 \mathrm{nM})$ and rat $(\mathrm{Ki}=$ $119 \mathrm{nM}$ ) recombinant 5-HT6 receptors. The double-blind placebo-controlled randomized efficacy and safety trial in 56 schizophrenic patients demonstrated that the severity of the negative symptoms was lower in the dimebolin group, and patients in the dimebolin group showed an improvement in cognitive dimensions such as working memory, attention, psychomotor coordination, and planning (Morozova et al. 2012). Clearly, more work is needed to elucidate the effects of 5-HT6 receptor antagonist when used in combination with standard antipsychotic treatments.

In conclusion, the present study provides evidence that 5HT6 receptor antagonism plays an important role in reversing the PPI deficits due to NMDA receptor blockade, and 5-HT2A/ 5-HT6 antagonism may represent an important element in the pharmacological profile for antipsychotic treatment.

Acknowledgments This study was supported by the Project "Prokog," UDA-POIG.01.03.01-12-063/09-02, co-financed by the European Union from the European Fund of Regional Development. The affinities of some ligands listed in this manuscript were provided by the National Institute of Mental Health's Psychoactive Drug Screening Program, Contract \# HHSN-271-2008-00025-C (NIMH PDSP). The NIMH PDSP (http://pdsp.med.unc.edu/) is directed by Bryan L. Roth MD, PhD at the University of North Carolina at Chapel Hill and Project Officer Jamie Driscol at NIMH, Bethesda MD, USA.

Open Access This article is distributed under the terms of the Creative Commons Attribution License which permits any use, distribution, and reproduction in any medium, provided the original author(s) and the source are credited.

\section{References}

Arnt J, Bang-Andersen B, Grayson B, Bymaster FP, Cohen MP, DeLapp NW, Giethlen B, Kreilgaard M, Mckinzie DL, Neill JC, Nelson DL, Nielsen SM, Poulsen MN, Schaus JM, Witten LM (2010) Lu AE58054, a 5-HT(6) antagonist, reverses cognitive impairment induced by subchronic phencyclidine in a novel object recognition test in rats. Int J Neuropsychopharmacol 13:1021-1033

Arvanov VL, Wang RY (1998) M100907, a selective 5-HT2A receptor antagonist and a potential antipsychotic drug, facilitates N-methyl-Daspartate-receptor mediated neurotransmission in the rat medial prefrontal cortical neurons in vitro. Neuropsychopharmacology 18:197-209

Auclair AL, Kleven MS, Besnard J, Depoortere R, Newman-Tancredi A (2006) Actions of novel antipsychotic agents on apomorphineinduced PPI disruption: influence of combined serotonin 5-HT1A receptor activation and dopamine D2 receptor blockade. Neuropsychopharmacology 31:1900-1909

Bakshi VP, Swerdlow NR, Geyer MA (1994) Clozapine antagonizes phencyclidine-induced deficits in sensorimotor gating of the startle response. J Pharmacol Exp Ther 271:787-794

Bast T, Zhang W, Feldon J, White IM (2000) Effects of MK801 and neuroleptics on prepulse inhibition: re-examination in two strains of rats. Pharmacol Biochem Behav 67:647-658

Boess FG, Monsma FJ Jr, Carolo C, Meyer V, Rudler A, Zwingelstein C, Sleight AJ (1997) Functional and radioligand binding characterization of rat 5-HT6 receptors stably expressed in HEK293 cells. Neuropharmacology 36:713-720

Borsini F (2011) International Review of Neurobiology. Volume 96: Pharmacology of 5-HT6 receptors, Part II. Academic Press

Braff DL, Geyer MA (1990) Sensorimotor gating and schizophrenia. Human and animal model studies. Arch Gen Psychiatry 47:181-188

Bubenikova V, Votava M, Horacek J, Palenicek T, Dockery C (2005) The effect of zotepine, risperidone, clozapine and olanzapine on MK-801disrupted sensorimotor gating. Pharmacol Biochem Behav 80:591-596

Cincotta SL, Rodefer JS (2010) Emerging role of sertindole in the management of schizophrenia. Neuropsychiatr Dis Treat 6:429-441

Daly DA, Moghaddam B (1993) Actions of clozapine and haloperidol on the extracellular levels of excitatory amino acids in the prefrontal cortex and striatum of conscious rats. Neurosci Lett 152:61-64

Dawson LA, Nguyen HQ, Li P (2001) The 5-HT(6) receptor antagonist SB271046 selectively enhances excitatory neurotransmission in the rat frontal cortex and hippocampus. Neuropsychopharmacology 25:662668

Dawson LA, Nguyen HQ, Li P (2003) Potentiation of amphetamineinduced changes in dopamine and 5 -HT by a $5-\mathrm{HT}(6)$ receptor antagonist. Brain Res Bull 59:513-521

Frederick JA, Meador-Woodruff JH (1999) Effects of clozapine and haloperidol on 5-HT6 receptor mRNA levels in rat brain. Schizophr Res 38:7-12

Gerard C, Martres MP, Lefevre K, Miquel MC, Verge D, Lanfumey L, Doucet E, Hamon M, El Mestikawy S (1997) Immuno-localization of serotonin 5-HT6 receptor-like material in the rat central nervous system. Brain Res 746:207-219

Geyer MA, Krebs-Thomson K, Braff DL, Swerdlow NR (2001) Pharmacological studies of prepulse inhibition models of sensorimotor gating deficits in schizophrenia: a decade in review. Psychopharmacology (Berl) 156:117-154

Glatt CE, Snowman AM, Sibley DR, Snyder SH (1995) Clozapine: selective labeling of sites resembling 5HT6 serotonin receptors may reflect psychoactive profile. Mol Med 1:398-406

Gravius A, Laszy J, Pietraszek M, Saghy K, Nagel J, Chambon C, Wegener N, Valastro B, Danysz W, Gyertyan I (2011) Effects of 5-HT6 antagonists, Ro-4368554 and SB-258585, in tests used for the detection of cognitive enhancement and antipsychotic-like activity. Behav Pharmacol 22:122-135 
Gururajan A, Taylor DA, Malone DT (2011) Effect of cannabidiol in a MK-801-rodent model of aspects of schizophrenia. Behav Brain Res 222:299-308

Hale AS, Azorin JM, Lemming OM, Maehlum E (2012) Sertindole in the long-term treatment of schizophrenia. Int Clin Psychopharmacol 27:231-237

Hart S, Zreik M, Carper R, Swerdlow NR (1998) Localizing haloperidol effects on sensorimotor gating in a predictive model of antipsychotic potency. Pharmacol Biochem Behav 61:113-119

Hatcher PD, Brown VJ, Tait DS, Bate S, Overend P, Hagan JJ, Jones DN (2005) 5-HT6 receptor antagonists improve performance in an attentional set shifting task in rats. Psychopharmacology (Berl) 181:253-259

Hirst WD, Stean TO, Rogers DC, Sunter D, Pugh P, Moss SF, Bromidge SM, Riley G, Smith DR, Bartlett S, Heidbreder CA, Atkins AR, Lacroix LP, Dawson LA, Foley AG, Regan CM, Upton N (2006) SB-399885 is a potent, selective 5-HT6 receptor antagonist with cognitive enhancing properties in aged rat water maze and novel object recognition models. Eur J Pharmacol 553:109-119

Hoffman DC, Donovan H, Cassella JV (1993) The effects of haloperidol and clozapine on the disruption of sensorimotor gating induced by the noncompetitive glutamate antagonist MK-801. Psychopharmacology (Berl) 111:339-344

Keith VA, Mansbach RS, Geyer MA (1991) Failure of haloperidol to block the effects of phencyclidine and dizocilpine on prepulse inhibition of startle. Biol Psychiatry 30:557-566

Klamer D, Svensson L, Fejgin K, Palsson E (2011) Prefrontal NMDA receptor antagonism reduces impairments in pre-attentive information processing. Eur Neuropsychopharmacol 21:248-253

Leng A, Ouagazzal A, Feldon J, Higgins GA (2003) Effect of the 5-HT6 receptor antagonists Ro04-6790 and Ro65-7199 on latent inhibition and prepulse inhibition in the rat: comparison to clozapine. Pharmacol Biochem Behav 75:281-288

Levin ED, Petro A, Caldwell DP (2005) Nicotine and clozapine actions on pre-pulse inhibition deficits caused by N-methyl-D-aspartate (NMDA) glutamatergic receptor blockade. Prog Neuropsychopharmacol Biol Psychiatry 29:581-586

Li Z, Huang M, Prus AJ, Dai J, Meltzer HY (2007) 5-HT(6) receptor antagonist SB-399885 potentiates haloperidol and risperidoneinduced dopamine efflux in the medial prefrontal cortex or hippocampus. Brain Res 1134:70-78

Long LE, Malone DT, Taylor DA (2006) Cannabidiol reverses MK-801induced disruption of prepulse inhibition in mice. Neuropsychopharmacology 31:795-803

Lundbeck (2008) Study ID: 12450A. ClinicalTrials.gov Identifier: 00810667. Title: Efficacy study exploring the effect of $\mathrm{Lu}$ AE58054 as augmentation therapy in patients with Schizophrenia

Maehara S, Hikichi H, Satow A, Okuda S, Ohta H (2008) Antipsychotic property of a muscarinic receptor agonist in animal models for schizophrenia. Pharmacol Biochem Behav 91:140-149

Maehara S, Satow A, Hikichi H, Ohta H (2011) Antipsychotic effects of $\mathrm{N}$-desmethylclozapine on sensorimotor gating function in rats-possible involvement of activation of M(1) muscarinic receptors. Eur J Pharmacol 667:242-249

McIntosh AL, Ballard TM, Steward LJ, Moran PM, Fone KC (2013) The atypical antipsychotic risperidone reverses the recognition memory deficits induced by post-weaning social isolation in rats. Psychopharmacology (Berl) 228: 31-42

Meltzer HY, Bastani B, Ramirez L, Matsubara S (1989) Clozapine: new research on efficacy and mechanism of action. Eur Arch Psychiatry Neurol Sci 238:332-339

Meneses A, Perez-Garcia G, Ponce-Lopez T, Castillo C (2011) 5-HT6 receptor memory and amnesia: behavioral pharmacology - learning and memory processes. Int Rev Neurobiol 96:27-47

Mitchell ES, Neumaier JF (2005) 5-HT6 receptors: a novel target for cognitive enhancement. Pharmacol Ther 108:320-333
Mitchell ES, Neumaier JF (2008) 5-HT6 receptor antagonist reversal of emotional learning and prepulse inhibition deficits induced by apomorphine or scopolamine. Pharmacol Biochem Behav 88:291-298

Mork A, Witten LM, Arnt J (2009) Effect of sertindole on extracellular dopamine, acetylcholine, and glutamate in the medial prefrontal cortex of conscious rats: a comparison with risperidone and exploration of mechanisms involved. Psychopharmacology (Berl) 206:39-49

Morozova MA, Beniashvili AG, Lepilkina TA, Rupchev GE (2012) Double-blind placebo-controlled randomized efficacy and safety trial of add-on treatment of dimebon plus risperidone in schizophrenic patients during transition from acute psychotic episode to remission. Psychiatr Danub 24:159-166

Newman-Tancredi A, Kleven MS (2011) Comparative pharmacology of antipsychotics possessing combined dopamine $\mathrm{D}(2)$ and serotonin 5-HT (1A) receptor properties. Psychopharmacology (Berl) 216:451-473

Pouzet B, Didriksen M, Arnt J (2002) Effects of the 5-HT(6) receptor antagonist, SB-271046, in animal models for schizophrenia. Pharmacol Biochem Behav 71:635-643

Riemer C, Borroni E, Levet-Trafit B, Martin JR, Poli S, Porter RH, Bos M (2003) Influence of the 5-HT6 receptor on acetylcholine release in the cortex: pharmacological characterization of 4-(2-bromo-6pyrrolidin-1-ylpyridine-4-sulfonyl)phenylamine, a potent and selective 5-HT6 receptor antagonist. J Med Chem 46:1273-1276

Rodefer JS, Nguyen TN, Karlsson JJ, Arnt J (2008) Reversal of subchronic PCP-induced deficits in attentional set shifting in rats by sertindole and a $5-\mathrm{HT}(6)$ receptor antagonist: comparison among antipsychotics. Neuropsychopharmacology 33:2657-2666

Rujescu D, Bender A, Keck M, Hartmann AM, Ohl F, Raeder H, Giegling I, Genius J, McCarley RW, Moller HJ, Grunze H (2006) A pharmacological model for psychosis based on N-methyl-D-aspartate receptor hypofunction: molecular, cellular, functional and behavioral abnormalities. Biol Psychiat 59:721-729

Schaffhauser H, Mathiasen JR, Dicamillo A, Huffman MJ, Lu LD, McKenna BA, Qian J, Marino MJ (2009) Dimebolin is a 5-HT6 antagonist with acute cognition enhancing activities. Biochem Pharmacol 78:1035-1042

Schreiber R, Vivian J, Hedley L, Szczepanski K, Secchi RL, Zuzow M, van Laarhoven S, Moreau JL, Martin JR, Sik A, Blokland A (2007) Effects of the novel 5-HT(6) receptor antagonist RO4368554 in rat models for cognition and sensorimotor gating. Eur Neuropsychopharmacol 17:277-288

Schwabe K, Koch M (2004) Role of the medial prefrontal cortex in Nmethyl-D-aspartate receptor antagonist induced sensorimotor gating deficit in rats. Neurosci Lett 355:5-8

Swerdlow NR, Bakshi V, Geyer MA (1996) Seroquel restores sensorimotor gating in phencyclidine-treated rats. J Pharmacol Exp Ther 279:1290-1299

Swerdlow NR, Braff DL, Geyer MA (2000) Animal models of deficient sensorimotor gating: what we know, what we think we know, and what we hope to know soon. Behav Pharmacol 11:185-204

Swerdlow NR, Geyer MA, Braff DL (2001) Neural circuit regulation of prepulse inhibition of startle in the rat: current knowledge and future challenges. Psychopharmacology (Berl) 156:194-215

Upton N, Chuang TT, Hunter AJ, Virley DJ (2008) 5-HT6 receptor antagonists as novel cognitive enhancing agents for Alzheimer's disease. Neurotherapeutics 5:458-469

Varty GB, Higgins GA (1995) Reversal of dizocilpine-induced disruption of prepulse inhibition of an acoustic startle response by the 5-HT2 receptor antagonist ketanserin. Eur J Pharmacol 287:201-205

Varty GB, Bakshi VP, Geyer MA (1999) M100907, a serotonin 5-HT2a receptor antagonist and putative antipsychotic, blocks dizocilpineinduced prepulse inhibition deficits in Sprague-Dawley and wistar rats. Neuropsychopharmacology 20:311-321 